\title{
Evaluation of the Role of Planned Conservative Surgery for Management of Morbidly Adherent Placenta
}

M.K.Alloush, M.I.Mohamed, Y.S.Idris and Y.J.Hussaein

Obstetrics and Gynecology, Dept., Faculty of Medicine, Benha Univ., Benha, Egypt

E-mail: ya48764@gmail.com

\begin{abstract}
Background: Placenta accreta, sometimes known as the "Obstetricians Nightmare," becomes the most problematic condition during the third stage of delivery. Placenta accreta is characterised by major persistent bleeding, blood loss of 3 to 5 litres, DIC, adult respiratory distress syndrome, large blood transfusion, electrolyte imbalance and renal failure. In this situation, even though a hysterectomy may save a woman's life, surgery comes with a host of risks, including damage to vital organs like the ureters and bladder, loss of fertility, and psychological stress. Thirty-eight percent of women who have peripartum hysterectomy do so due to placenta accreta. Maternal mortality may occur despite strong planning, discipline control, and transfusion management. Obstetricians have developed a range of conservative approaches for placenta accreta treatment due to the need of fertility preservation and uterine preservation in many patients. According to the study's goal, planned conservative surgery for morbidly adherent placenta management may minimise maternal mortality and morbidity while improving quality of life. Methods: Fifty individuals having a clinical diagnosis of MAP were enrolled in this prospective trial. Between June 2019 and March 2021, planned conservative surgery was performed at Benha University Hospital's Obstetrics and Gynecology Department in Benha, Egypt. After conservative surgery failed in 16\% of instances, patients had C/S and myometrial excision of the region of the uterus occupied by an attached placenta. Of those, $56 \%$ underwent $\mathrm{C} / \mathrm{S}+\mathrm{bilateral}$ uterine artery ligation. Of those, $28 \%$ underwent hysterectomy. When it came to pregnancy-related issues, $84 \%$ of women were free of them, but $16 \%$ had bladder damage, and $96 \%$ were free of difficulties, but $4 \%$ had ureter damage. Ninetyfour percent of pregnancies ended in singletons, with three percent (three occurrences) in twin pregnancies, and the average birth weight was 2.75 kilogrammes $(\mathrm{kg})$. There were $2 \%$ IUFD admitted to the nursery, $28 \%$ admitted to the incubator and 70\% released in good condition according to perinatal mortality, the death rate being $13 \%$ (6 instances). To sum up, conservative management is a choice for patients who have been appropriately advised and prepared, especially for women who desire the possibility of future pregnancy and who agree to careful follow up in facilities with suitable technology and resources, especially
\end{abstract}

Key words: Planned Conservative Surgery, Adherent Placenta.

\section{Introduction}

Refers to uterine wall-attached, difficult-toseparate placenta. We don't know the specific mechanism by which placental attachment abnormalities are set in motion, but we do know that aberrant decidualization of a scarred region or the absence of decidua in the lower uterine segment close to the cervix are not sufficient [1].

Placental tissue (trophoblast) invades the outer or inner myometrium or the uterine serosa abnormally in Morbidly Adherent Placenta (MAP) (termed as accreta, increta, percreta respectively). It's a potentially deadly disorder that kills $7-10 \%$ of women in childbirth. Morbidly adherent placentas develop when decidua basalis and the Nitabuch layer are absent completely [2].

Placenta accreta affected one in every 4027 pregnancies in the 1970 s, one in every 2510 pregnancies in the 1980 s, one in every 533 pregnancies from 1982 to 2002, and one in every 210 pregnancies in 2006. Because of the rising number of caesarean sections, there has been an enormous rise in the incidence of MAP. The two most significant risk factors are a previa and a previous caesarean section, and both are more probable than not. In addition, past uterine surgery, dilatation and curettage, prior history of MRP, ashermann syndrome (endometrial abnormalities), submucous leio-myoma, advanced maternal age, and many pregnancies are also risk factors to consider [3].

Antenatal diagnosis is essential since the effects of an undiscovered placenta accreta may be severe. Reduced bleeding and fewer blood transfusions are linked to prenatal diagnosis, probably because these women are more likely to get haemorrhage prevention medications and have their placentas less often removed [4].

It's more difficult to diagnose MAP, and medical imaging may be the best way to find out whether it's there. For this reason, transvaginal sonography is widely accepted as the best approach for pinpointing the exact location of the placenta when it is buried deep in the uterus. Even when there is vaginal bleeding, TVS is safe for women with placenta previa. TVS has great accuracy rates $(87.5 \%$ sensitivity, $98 \%$ specificity, and a positive predictive value of $93 \%$ ), making it the gold standard for diagnosing placental abnormalities [5].

A loss of continuity of the uterine wall in the second and third trimesters, multiple vascular lacunae (irregular vascular spaces) within the uterus, and a Swiss cheese appearance near the placental implantation site are all seen on gray-scale sonography during this time period. Additionally, there is no hypoechoic border (myometrial zone) between the 
placenta and myometrium, and the placental/myometrial site bulges [6].

Histopathological diagnosis of placental invasion, clinical evaluation of aberrant placenta adherence, or surgical proof of severe placental invasion are commonly used to confirm a morbidly adhered placenta [7].

According to the study's goal, planned conservative surgery for morbidly adherent placenta management may minimise maternal mortality and morbidity while improving quality of life.

\section{Patients and Methods}

This prospective study included 50 patients with clinical diagnosis of MAP Planned Conservative Surgery was done at the Obstetrics and Gynecology Department, Benha University Hospital, Benha, Egypt during the period from June 2019 to March 2021.

\section{Inclusion criteria}

1. Gestational age more than 28 weeks as determined by first day of last menstrual period and confirmed by ultrasound.

2. Placenta previa anterior or posterior; major or minor degree as confirmed by ultrasound.

3. Clinically stable with no or mild vaginal bleeding that do not require immediate interference.

4. No evidence of fetal compromise.

5. There is a need to conserve the uterus for future fertility.

6. Agreed to participate in the study.

\section{Methods:}

Patients who fulfilled inclusion criteria were asked to give informed consent for the study and those who gave the consent were subjected to the following:

- Demographic data including age, parity, gestational age and previous caesarean delivery or other uterine surgery.

- Medical and obstetric history.

- Complete general, abdominal and obstetric examination.

\section{Investigations}

a. Complete blood count.

b. Blood group and Rh typing.

c. Random blood sugar.

d. Coagulation profile.

e. Renal and liver function tests.

f. Routine urine analysis.

g. Cross matched blood.

- Grey-scale and color Doppler ultrasound performed in all cases to obtain maternal clinical characteristics and ultra sound findings. Routine ultrasound scan was done at weekly interval using 3.5 MHZ abdominal probe (Voluson $730 \mathrm{PRO} \mathrm{V,}$ GE Healthcare, USA).

- All Cases of placenta accreta were managed by conservative surgery in the form of bilateral uterine artery ligation and myometrial resection (pelvic devascularization, placental extirpation, compression sutures, triple $\mathrm{P}$ procedure and internal iliac artery ligation) as appropriate.

- If conservative surgery failed due to uncontrolled bleeding cesarean hystrectomy was done as life saving procedure.

Outcome measures:

Outcome measures included:

- Intraoperative data including placental location, estimated blood loss, blood transfusion, presence of placenta accreta and procedures needed to control bleeding.

- Maternal outcome (complications like bladder or ureteric injury or need for blood transfusion or admission for ICU) and neonatal outcome for birth weights, nursery admission and perinatal mortality.

Administrative design:

Patients were counseled for different diagnostic options and a written informed consent was signed. The study was approved from Ethical Committee of the Hospital.

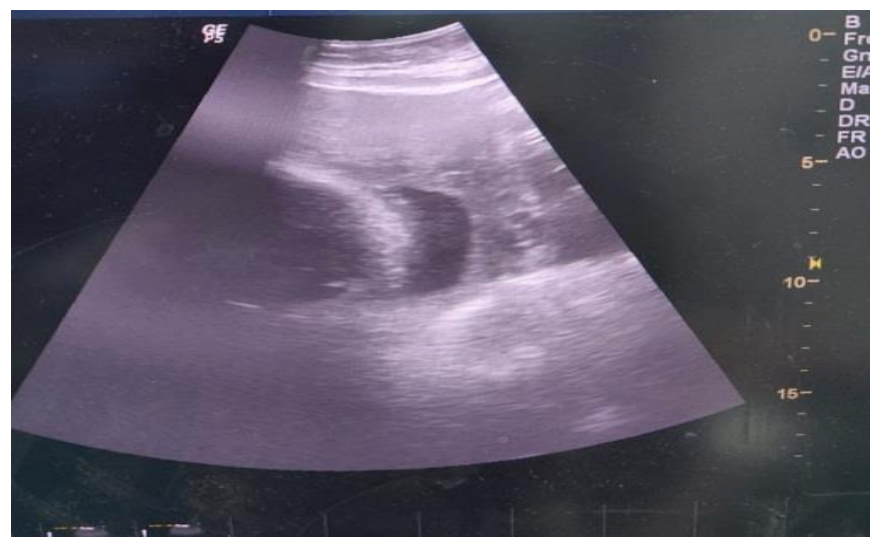

Fig. (1) a case of placenta previa complete centralis anterior suspected accreta. 


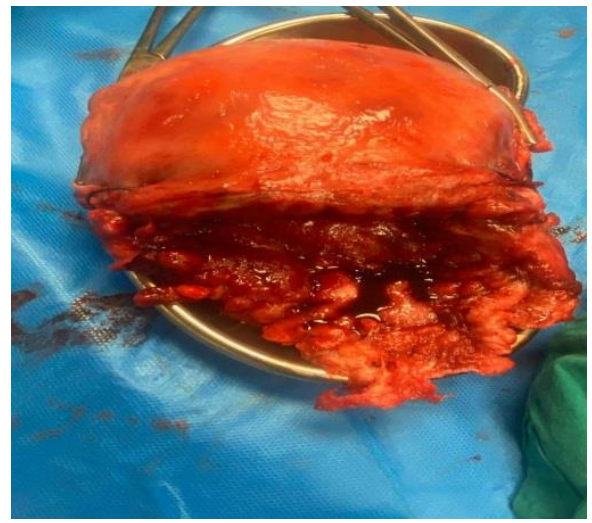

Fig. (2) a specimen of postoperative hystrectomy in case of placenta previa complete centralis anterior accreta.

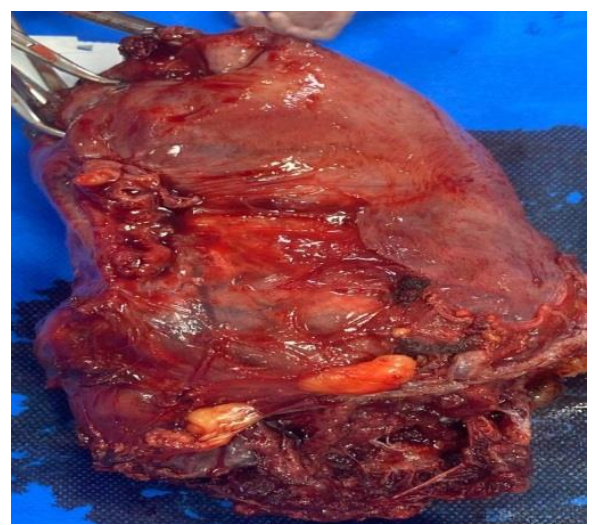

Fig. (3) a specimen of postoperative hystrectomy in case of placenta previa complete centralis anterior accreta.

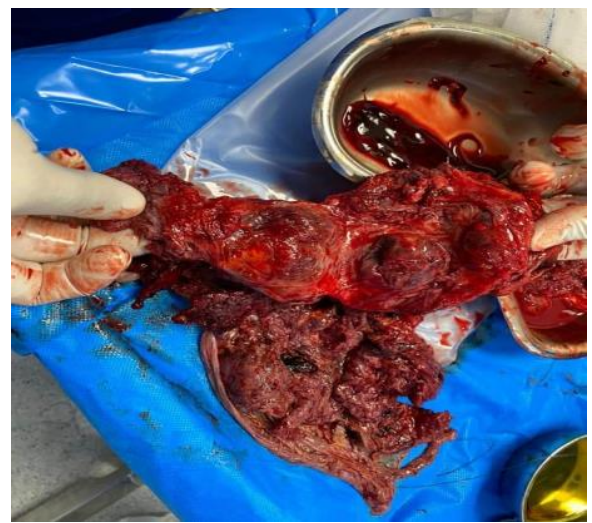

Fig. (4) a specimen of postoperative hystrectomy in case of placenta previa complete centralis anterior accreta.

The clinical data were recorded on a report form. These data were tabulated and analysed using the computer program SPSS (Statistical package for social science) version 26 .

\section{Results}

Table (1): showed that there is no statistical difference between different management lines according to the parity or gestational age but there was difference according to the mean age in which conservative management is much lower than hysterectomy.
Table (2): show that there no statically difference according the site of placenta but there was significant statically difference between three management according to the degree of placenta and number of $\mathrm{C} / \mathrm{S}$.

Table (3): showed that there is no significant statically difference between two management lines according to the neonatal outcome.

Table (4) shows distribution of maternal outcome in relation to Blood transfusion, duration of Operation, occurrence of visceral injury, ICU admission and surgical site infection. 
Table (1) Comparison between different management lines according to age, parity, gestational age.

\begin{tabular}{|c|c|c|c|c|c|c|}
\hline \multirow[t]{2}{*}{ Management } & \multicolumn{2}{|c|}{$\begin{array}{c}\text { Conservative } \\
\text { management } \\
(36)\end{array}$} & \multicolumn{2}{|c|}{$\begin{array}{c}\text { Hysterectomy } \\
\text { (14) }\end{array}$} & \multirow[t]{2}{*}{$\begin{array}{c}\text { Statistical } \\
\text { test }\end{array}$} & \multirow[t]{2}{*}{ P value } \\
\hline & No & $\%$ & No & $\%$ & & \\
\hline Age $\quad$ Mean \pm SD & \multicolumn{2}{|c|}{$28.69 \pm 5.09$} & \multicolumn{2}{|c|}{$32.43 \pm 3.52$} & St $\mathrm{t}=2.51$ & $0.015^{*}$ \\
\hline \multicolumn{7}{|l|}{ Parity } \\
\hline 0 & 1 & 2.8 & 0 & 0.0 & \multirow[t]{6}{*}{$\mathrm{FET}=9.18$} & \multirow[t]{6}{*}{0.068} \\
\hline 1 & 5 & 13.9 & 0 & 0.0 & & \\
\hline 2 & 11 & 30.6 & 5 & 35.7 & & \\
\hline 3 & 8 & 22.2 & 2 & 14.3 & & \\
\hline 4 & 5 & 13.9 & 7 & 50.0 & & \\
\hline 6 & 6 & 16.7 & 0 & 0.0 & & \\
\hline \multicolumn{7}{|l|}{ GA } \\
\hline Mean \pm SD & \multicolumn{2}{|c|}{$36.03 \pm 2.58$} & \multicolumn{2}{|c|}{$36.36 \pm 1.74$} & St $t=0.44$ & 0.66 \\
\hline
\end{tabular}

Table (2) Comparison between different management lines according to site of placenta, degree of placenta, number of previous CS.

\begin{tabular}{|c|c|c|c|c|c|c|}
\hline \multirow[t]{2}{*}{ Management } & \multicolumn{2}{|c|}{$\begin{array}{c}\text { Conservative } \\
\text { management } \\
(36)\end{array}$} & \multicolumn{2}{|c|}{$\begin{array}{c}\text { Hysterectomy } \\
\text { (14) }\end{array}$} & \multirow[t]{2}{*}{$\begin{array}{c}\text { Statistical } \\
\text { test }\end{array}$} & \multirow[t]{2}{*}{$P$ value } \\
\hline & No & $\%$ & No & $\%$ & & \\
\hline \multicolumn{7}{|l|}{ Site of placenta } \\
\hline Anterior & 30 & 83.3 & 14 & 100 & $\mathrm{FET}=1.31$ & 0.17 \\
\hline Posterior & 6 & 16.7 & 0 & 0.0 & & \\
\hline \multicolumn{7}{|l|}{ Degree } \\
\hline Major & 23 & 63.9 & 13 & 92.9 & $\mathrm{FET}=10.37$ & $0.003 * *$ \\
\hline Minor & 13 & 36.1 & 1 & 7.1 & & \\
\hline \multicolumn{7}{|c|}{ No of previous CS } \\
\hline \multicolumn{7}{|c|}{0} \\
\hline 1 & 11 & 30.6 & 0 & 0.0 & & \\
\hline 2 & 3 & 8.3 & 1 & 7.1 & $\mathrm{FET}=9.36$ & \\
\hline 3 & 15 & 41.7 & 6 & 42.9 & & $0.034 *$ \\
\hline \multirow[t]{2}{*}{4} & 5 & 13.9 & 3 & 21.4 & & \\
\hline & 2 & 5.6 & 4 & 28.6 & & \\
\hline
\end{tabular}

Table (3) Comparison between different management lines according to neonatal outcome.

\begin{tabular}{|c|c|c|c|c|c|c|}
\hline \multirow[t]{2}{*}{ Management } & \multicolumn{2}{|c|}{$\begin{array}{c}\text { Conservative } \\
\text { management (36) }\end{array}$} & \multicolumn{2}{|c|}{ Hysterectomy (14) } & \multirow[t]{2}{*}{ Statistical test } & \multirow[t]{2}{*}{ P value } \\
\hline & No & $\%$ & No & $\%$ & & \\
\hline \multicolumn{7}{|l|}{ Neonatal outcome } \\
\hline Single & $\begin{array}{c}2 \\
34\end{array}$ & $\begin{array}{c}5.6 \\
94.4\end{array}$ & $\begin{array}{c}1 \\
13\end{array}$ & $\begin{array}{c}7.1 \\
92.9\end{array}$ & $\mathrm{FET}=0.0$ & 1.0 \\
\hline $\begin{array}{l}\text { Birth wt Mean } \pm \text { SD } \\
\text { Nursery admission }\end{array}$ & $\begin{array}{c}2.78 \pm 0.515 \\
0\end{array}$ & 0.0 & $\begin{array}{c}2.76 \pm 0.514 \\
1\end{array}$ & 7.1 & 0.13 & 0.90 \\
\hline IUFD & 10 & 27.8 & 9 & 64.3 & $\mathrm{FET}=2.42$ & \\
\hline $\begin{array}{l}\text { Yes } \\
\text { No }\end{array}$ & 26 & 72.2 & 4 & 28.6 & & 0.41 \\
\hline $\begin{array}{l}\text { Perinatal mortality } \\
\text { Yes } \\
\text { No }\end{array}$ & $\begin{array}{c}4 \\
32\end{array}$ & $\begin{array}{l}11.1 \\
88.9\end{array}$ & $\begin{array}{c}2 \\
12\end{array}$ & $\begin{array}{l}14.3 \\
85.7\end{array}$ & $\mathrm{FET}=0.0$ & 1.0 \\
\hline
\end{tabular}


Table (4) maternal outcome.

\begin{tabular}{|l|c|c|}
\hline Outcome & Conservative Management & CS Hystrectomy \\
\hline Blood transfusion & $\mathbf{1 0 0 \%}$ & $\mathbf{1 0 0 \%}$ \\
-RBC'S & $1-3$ & $1-6$ \\
-FFP & $1-2$ & $1-2$ \\
-Platelets & - & 1 \\
\hline Duration of Operation & $50-120 \mathrm{~min}$. & $130-250 \mathrm{~min}$. \\
\hline bladder injury & $5(10 \%)$ & $3(6 \%)$ \\
\hline Ureter injury & $-(0 \%)$ & $2(4 \%)$ \\
\hline ICU admission & $1(2 \%)$ & $3(6 \%)$ \\
\hline Surgical site infection & $-(0 \%)$ & $1(2 \%)$ \\
\hline
\end{tabular}

\section{Discussion}

There were no difficulties for $84 \%$ of the mothers in the research, whereas just $8 \%$ of the mothers suffered bladder injuries that complicated things ( 5 cases in conservative management group and 3 cases in CS hysterectomy group). A total of four of the study's subjects were hospitalised (one case in conservative management group and 3 cases in CS hysterectomy group).

Ureteric damage complicated the care of two patients undergoing CS Hysterectomy, although none of the patients in the conservative therapy group did. A surgical site infection complicated one Cs hystrectomy case, while no patients were infected in the conservative care line.

The blood transfusion rate differed significantly between the study's two groups (4 cases in hysterectomy management line needed blood transfusion while 2 cases in conservative line management needed blood transfusion).

CS hysterectomy group had a lengthier operating time (130-250 min.) than the conservative treatment group in terms of surgical operation duration (50-120 min.)

For example, from August 2014 to May 2015, one study done by Shehata [8] at Tanta University in Tanzania employed conservative management by a three-step approach, firstly, the use of double-uterine artery ligation on both sides, secondly, stitching the placental bed, and thirdly, the use of a triple-way catheter through the cervix and inflation of 50-cc saline to compress and drain bleeding. (CS and myomertial excision, CS and uterine arterial ligation) were employed in our investigation, although the prevalence of maternal complications was quite comparable in both studies $(13.3 \%$ of patients experienced bladder damage in Shehata [8] study as opposed to $16 \%$ ).

There were six instances in our research when blood transfusion was required, whereas there were none in Shehata. When doing research, transfusions were required.

Shehata has had no incidents. In one research, admission to the intensive care unit was required, but in our investigation, ICU admission was required in four out of the eight instances (one case in conservative management group and 3 cases in CS hysterectomy group).

This may be due to the difference in the number of patients in the two studies, with our study having 50 patients while Abdel Khalek et al. [9] had 74, which could explain the difference in the number of CS hystrectomy cases. Our study found that 14 cases (28 percent) had the procedure, while 44 cases (62.9 percent) had it. There were eight instances (16 percent) in our analysis that differed from the Abdel khalek et al (5cases in conservative management group and 3 cases in CS hysterectomy group). were accompanied by bladder damage, but in the Abdel khalek et al. [9] investigation, 17 patients (24.3 percent) were complicated by bladder injury (4 cases in conservative management group and 13 cases in CS hysterectomy group ). Whereas no patients in the conservative treatment group experienced ureteric damage in our research, Abdel khalek et al. [9] found that four cases in the CS Hysterectomy management group were complicated by ureteric injury while no instances in the conservative management group did.

Only six patients in our research required blood transfusion, but all cases in the Abdel khalek et al. [9] study received packed red cells and fresh frozen palsma, according to the comparison of the blood transfusion rates.

A total of four of the study's subjects were hospitalised (one case in conservative management group and 3 cases in CS hysterectomy group). While in the Medhat research, 8 patients (11.4 percent) were admitted to the post-operative intensive care unit (ICU). (5 cases in the CS hysterectomy group vs. 1 in conservative treatment)

According to our research, surgery took between 130 and 250 minutes for women who had a laparoscopic CS hysterectomy and between 50 and 120 minutes for those who underwent conservative care (45-120 min.)

In our research, the incidence of maternal concern for bladder damage was lower than in another study by chaudhari et al [10] (10 percent in chaudhari et al compared to (16 percent in our study).

Nevertheless, the number of patients who required ICU admission was larger in the research by chaudhari et al [10] (13 percent) than in ours (8\%). 
Surgery-site infection rates were lower in our research than in the study by chaudhari et al (10\%) ( $13 \%$ vs. $19 \%$ in our study) ( 2 percent in our study). [10] Our trial had a lower complication rate than another one, called pri-paz, since complications occurred less often.

It was shown that the incidence of bladder damage was higher in the pri-paz et al research $(11 \%)$ than in the (54.1 percent).

In the pri-paz et al [11] research, 14 patients were hospitalised to the ICU, but in our study, only four patients were.

Pri-paz et al [11] studied all patients and found that only six required blood transfusions in their research; in our investigation, this was not the case.

\section{Conclusion}

Patients who are appropriately advised and prepared, in particular women who desire the possibility of future pregnancy and who agree to careful follow up, might choose conservative treatment in facilities with suitable technology and resources.

\section{References}

[1] CH.Comstock, RA.Bronsteena, The antenatal diagnosis of placenta accrete. BJOG.vol. 121, pp.171-182, 2014.

[2] A.Pinas-Carrillo and E.Chandraharan, Management of morbidly adherent placenta. Obstet Gynaecol Reproduc Med.vol.26,pp.28390.

[3] Committee on Obstetric Practice. Committee Opinion no.529. Placenta accreta. Obstet Gynecol.vol.120, pp. 207-11, 2012.

[4] K.Fitzpatrick, S.Sellers, P.Spark, et al., The management and outcomes of placenta accreta, increta, and percreta in the UK: a populationbased descriptive study. BJOG.vol. 121, pp. 6271, 2014.

[5] IE.Timor-Tritsch, RA.Yunis, Confirming the safety of transvaginal sonography in patients suspected of placenta previa. Obstet Gynecol.vol.81, pp.742-4,1993.

[6] M.Shawky, E.AbouBieh, A.Masood, Gray scale and Doppler ultrasound in placenta accreta: Optimization of ultrasound signs. Egyptian $\mathbf{J}$ Radiol Nuclear Medic.vol. 47,pp. 1111-5, 2016.

[7] AG.Eller, TF.Porter, P.Soisson, et al., Optimal management strategies for placenta accreta. BJOG.vol.116,pp.648-54, 2009.

[8] A.SHEHATA, Uterine sparing techniques in placenta accreta. Obstet Gynecol Int J.vol. 5,pp.00143, 2016.

[9] Abdel Khalek, E.Medhat Abdel, et al. Menoufia University Hospital experience in management of the patients with morbidly adherent placenta. Menoufia Medical Journal.vol. 33, pp. 480, 2020.
[10] H. K.Chaudhari, P. K.Shah, N.D’Souza, Morbidly Adherent Placenta: Its Management and Maternal and Perinatal Outcome. The Journal of Obstetrics and Gynecology of India.vol. 67,pp.42-47, 2017.

[11] Shai.PRI-PAZ, et al. Comparison between emergent and elective delivery in women with placenta accreta. The Journal of Maternal-Fetal \& Neonatal Medicine.vol.26,pp.1007-1011, 2013. 